\title{
Temperature-dependent effect of filamentous cyanobacteria on Daphnia magna life history traits
}

\author{
Anna BEDNARSKA*, Joanna ŁOŚ and Piotr DAWIDOWICZ \\ Department of Hydrobiology, Faculty of Biology, University of Warsaw, Banacha 2, 02-097 Warsaw, Poland \\ *e-mail corresponding author: a.bednarska@uw.edu.pl
}

\begin{abstract}
Filamentous cyanobacteria are unsuitable food for Daphnia due to their poor manageability, poor nutritional value and, in some cases, toxicity. As the strength of harmful effects of cyanobacteria on filter-feeding zooplankton is temperature dependent, the global warming scenarios for eutrophic lakes in temperate zone might include an escalated suppression of Daphnia populations caused by the presence of cyanobacterial filaments. To test this assumption, we conducted life-table experiments with four clones of Daphnia magna fed either a green alga Scenedesmus obliquus or a non-toxic strain of filamentous cyanobacteria Cylindrospermopsis raciborskii in two temperatures $\left(20^{\circ} \mathrm{C}\right.$ and $\left.24^{\circ} \mathrm{C}\right)$. Key life history parameters of Daphnia, i.e., age and size at first reproduction, fecundity, and individual growth rate, were measured. Both food and temperature significantly affected Daphnia performance, however, the effect of interaction of these two factors was ambiguous and highly genotype-dependent. We conclude that the temperature increase within the studied range will not necessarily strengthen the suppression of Daphnia growth by filamentous cyanobacteria, but may affect clonal selection within population of Daphnia, thus possibly triggering microevolutionary changes within affected populations.
\end{abstract}

Key words: inter-clonal differences, non toxic cyanobacteria, global warming, life history

\section{INTRODUCTION}

In the last decades, increased frequency and extended duration of cyanobacteria blooms can be seen in temperate lakes. It is commonly accepted that expansion of cyanobacteria in summer phytoplankton communities is associated with anthropogenic changes of environment, mainly with eutrophication (e.g., Lampert \& Sommer 1993; Wetzel 2001). Cyanobacteria are an insufficient food source for filter-feeding zooplankton due to their toxicity (DeMott 1999), poor manageability due to interference with food gathering process (Gliwicz $\&$ Siedlar 1980), and nutritional inadequacy, i.e., deficiency in essential nutrients such as sterols, polyunsaturated fatty acids and others yet unidentified compounds (Von Elert et al. 2003). The presence of cyanobacteria can trigger various changes of behaviour, morphology and life history of herbivore planktonic cladocerans, especially of the genus Daphnia (Lampert 1987a; deBernardi \& Giussani 1990).

It has been shown that negative effect of cyanobacteria on Daphnia is temperature-dependent. Claska \& Gilbert (1998) showed that under elevated temperature, Daphnia are more sensitive to both toxic cyanobacteria and pure cyanotoxin than their conspecifics exposed to the same toxin at lower temperature. Moreover, sterol limitation of Daphnia fed with cyanobacteria can be intensified by elevated temperatures, due to increase in Daphnia demands for sterols with rising temperatures (Sperfeld \& Wacker 2009). Increase in ambient temperature resulted in a decrease in growth rate of Daph- nia fed cyanobacteria (Abrusán 2004). Reduced fecundity of daphnids as a result of interaction of elevated temperature with presence of filamentous cyanobacteria and algae was also demonstrated in in situ experiments (Threlkeld 1979).

Different climate scenarios predict the increase of global average temperature between about $1.1{ }^{\circ} \mathrm{C}$ and $6.4{ }^{\circ} \mathrm{C}$, with average rise of $3.9^{\circ} \mathrm{C}$, by the end of this Century (IPCC 2007). The summer phytoplankton of eutrophic temperate lakes is already dominated by cyanobacteria, which generally grow well at elevated temperatures (Rapala \& Sivonen 1998). Thus the temperature increase may strengthen the negative effect of cyanobacteria on Daphnia fitness, because (i) Daphnia are more affected by cyanobacteria at higher temperature and (ii) global warming is expected to promote cyanobacteria expansion and to lead to increased frequency and magnitude of cyanobacteria blooms (Paerl \& Huisman 2008).

To test the hypothesis that a higher temperature increases the negative influence of cyanobacteria on Daphnia, four clones of Daphnia magna were fed with non-toxic strain of filamentous cyanobacterium Cylindrospermopsis raciborskii or green alga Scenedesmus obliquus at two temperatures, i.e. $20^{\circ} \mathrm{C}$, which represents averaged current thermal conditions in the epilimnetic zone of temperate lakes in summer, and $24^{\circ} \mathrm{C}$, which simulates conditions after forecasted global warming.

Cylindrospermopsis raciborskii, the cyanobacterium used in the study, is under a particular concern in rela- 
tion to water quality management and the impact of the forecasted global warming on lakes phytoplankton assemblies. The species was originally described as subtropical but recently it has been found in growing number of mid-latitude lakes including many lakes across northern Europe (Padisák 1997). Rapid spread of this cyanobacterium is usually linked with climate change as well as with its wide physiological tolerance (Briand et al. 2004; Wiedner et al. 2007).

\section{MATERIALS AND METHODS}

Four clones of Daphnia magna Strauss (K1, K2, K3, K4) were used in the experiments. All clones were hatched at least 1 year prior to the study from ephippia isolated in our laboratory from sediments originating from Książęca pond, Warsaw, Poland. The clones were maintained in laboratory batch cultures at room temperature $\left(19-22{ }^{\circ} \mathrm{C}\right)$ and were fed with the green alga Scenedesmus obliquus. To establish clonal lineages used in the experiments, a single female from each clonal culture was selected. To standardize the animals from studied clones and to minimize the potential differences between clones, caused by differences in culturing conditions of the mothers, clonal lineages were precultured for at least 3 generations (second clutch offspring were always taken for further culturing) under standard conditions, i.e., in the temperature-controlled water bath (22 ${ }^{\circ} \mathrm{C} \pm 0.5{ }^{\circ} \mathrm{C}$ ), summer photoperiod (16L:8D), fed daily with S. obliquus $\left(1 \mathrm{mg} \mathrm{C} \mathrm{L}^{-1}\right), 50 \mathrm{ml}$ of medium $\times$ ind $^{-1}$, culture medium changed every other day.

The experiments were performed under two temperatures, $20^{\circ} \mathrm{C}$ and $24{ }^{\circ} \mathrm{C}$. The filaments of non-toxic strain of cyanobacteria Cylindrospermopsis raciborskii or the green alga Scenedesmus obliquus as reference food, in concentrations of $1 \mathrm{mg} \mathrm{C} \mathrm{L}^{-1}$ were offered as a food source in the two temperatures.

The experimental media were prepared with lake water from a small eutrophic Lake Janówek located near Warsaw, prefiltered through 1-mm filter and conditioned in a large, aerated tank for 2 weeks before use. To prepare experimental media, the water was filtered again through $0.2-\mu \mathrm{m}$ filter and enriched with suspension of food (either green algae or cyanobacteria). Both green algae and the cyanobacteria were cultured in xenic (containing bacteria) batch cultures on $\mathrm{Z} / 4$ algal medium, under room temperature $\left(20^{\circ} \mathrm{C} \pm 0.5^{\circ} \mathrm{C}\right)$, constant illumination, and aeration.

Second-clutch neonate females (aged $\leq 20 \mathrm{~h}$ ) were randomly assigned to one of the four experimental treatments (10 individuals kept separately in each treatment), and 25 additional newborns were dried and weighted to determine initial body mass. The experiments were preformed in temperature-controlled water baths under summer photoperiod (16L:8D); the culture media were changed daily. All animals were kept individually in $100 \mathrm{~mL}$ glass vessels until first eggs were laid into brood chamber. Age at first reproduction
(AFR) was recorded. Primiparous Daphnia were photographed, the eggs were counted under the stereomicroscope, and the animals were dried and weighed (Orion Cahn C-35 Ultra-Microbalance, Thermo Electron Corporation, USA) to calculate growth rate. Dry masses were converted into somatic growth rates per day using the formula $g_{i}=\left(\ln \left[M_{t}\right]-\ln \left[M_{0}\right]\right) t^{-1}$, where $M_{0}$ and $M_{t}$ are the masses of the animals at the start and at the end of experiment, respectively, and $t$ is the experiment duration. The body length of Daphnia at first reproduction (SFR) was measured from the photographs using MultiScan image analysis software (Computer Scanning Systems, Warsaw, Poland). The statistical analysis of the data, three-way ANOVA followed by Tukey HSD post hoc analysis, was performed with the Statistix 9.0 software. The data concerning fecundity of Daphnia were ln-transformed to achieve homogeneity of variances.

\section{RESULTS}

Food type, temperature and genotype (clone) significantly affected measured parameters of life history of Daphnia (Tab. 1, Figs 1, 2, 3 and 4). The animals fed with green alga matured earlier, at larger body size, they had almost four times more eggs, and grew more than two times faster than their clonemates fed with cyanobacteria. As expected, the temperature affected Daphnia life history as well. Animals reared at lower temperature $\left(20{ }^{\circ} \mathrm{C}\right)$ grew slower, matured later, but attained larger body size and had more eggs than animals kept at higher temperature $\left(24^{\circ} \mathrm{C}\right)$. Clonal origin was also a significant source of variation in life history of studied Daphnia (Figs 1, 2, 3 and 4, Tab. 1).

Interactions of food type and genotype and temperature and genotype were significant sources of variation in all studied parameters of Daphnia life history (Tab. 1). Tukey HSD post hoc analysis (at $\alpha=$ 0.05 ) revealed the biggest differences between food treatments in the clone $\mathrm{K} 3$ and the smallest in the clone $\mathrm{K} 4$. Only in the K1 clone the temperature significantly affected all measured life history parameters, whereas in the clone K2 only AFR and growth rate were slightly affected by temperature (Figs 1, 2, 3 and 4). Interaction of food type and temperature significantly affected only one of four studied life history parameters, age at first reproduction (Tab. 1). Although increase of temperature always resulted in shortening the age at first reproduction, the decrease of AFR due to higher temperature was stronger for animals kept in presence of cyanobacteria (Fig. 1 panel A and B).

Interaction of three parameters: food type, temperature and genotype, was a significant source of variation in all measured life history parameters (Tab. 1, Figs 1, 2, 3 and 4). In general, feeding on cyanobacteria prolonged time needed to reach maturity, and in animals fed with cyanobacteria significant differences between temperatures were found in all clones but when fed with green algae only animals from clones K3 and K4 matured sig- 
Tab. 1. Three-way ANOVA testing the effects of genotype (Clone), type of food (S. obliquus vs C. raciborskii) and temperature on life history parameters of Daphnia magna.

\begin{tabular}{|c|c|c|c|c|}
\hline Life history parameter & Source & $\mathrm{df}$ & $\mathrm{F}$ & $p$ \\
\hline AFR & $\begin{array}{l}\text { Food } \\
\text { Temperature } \\
\text { Clone } \\
\text { Food } \times \text { Temperature } \\
\text { Food } \times \text { Clone } \\
\text { Temperature } \times \text { Clone } \\
\text { Food } \times \text { Temperature } \times \text { Clone } \\
\text { Error }\end{array}$ & $\begin{array}{c}1 \\
1 \\
3 \\
1 \\
3 \\
3 \\
3 \\
142\end{array}$ & $\begin{array}{c}1097.49 \\
383.94 \\
53.53 \\
118.31 \\
83.44 \\
13.50 \\
27.25\end{array}$ & $\begin{array}{l}<0.0001 \\
<0.0001 \\
<0.0001 \\
<0.0001 \\
<0.0001 \\
<0.0001 \\
<0.0001\end{array}$ \\
\hline SFR & $\mid \begin{array}{l}\text { Food } \\
\text { Temperature } \\
\text { Clone } \\
\text { Food } \times \text { Temperature } \\
\text { Food } \times \text { Clone } \\
\text { Temperature } \times \text { Clone } \\
\text { Food } \times \text { Temperature } \times \text { Clone } \\
\text { Error }\end{array}$ & $\begin{array}{c}1 \\
1 \\
3 \\
1 \\
3 \\
3 \\
3 \\
142\end{array}$ & $\begin{array}{c}773.58 \\
32.84 \\
101.37 \\
0.66 \\
15.51 \\
5.93 \\
5.95\end{array}$ & $\begin{array}{c}<0.0001 \\
<0.0001 \\
<0.0001 \\
0.4194 \\
<0.0001 \\
0.008 \\
0.007\end{array}$ \\
\hline Number of eggs & $\begin{array}{l}\text { Food } \\
\text { Temperature } \\
\text { Clone } \\
\text { Food } \times \text { Temperature } \\
\text { Food } \times \text { Clone } \\
\text { Temperature } \times \text { Clone } \\
\text { Food } \times \text { Temperature } \times \text { Clone } \\
\text { Error }\end{array}$ & $\begin{array}{c}1 \\
1 \\
3 \\
1 \\
3 \\
3 \\
3 \\
142\end{array}$ & $\begin{array}{c}875.50 \\
35.70 \\
16.85 \\
0.15 \\
5.00 \\
8.53 \\
8.91\end{array}$ & $\begin{array}{c}<0.0001 \\
<0.0001 \\
<0.0001 \\
0.7035 \\
0.0025 \\
<0.0001 \\
<0.0001\end{array}$ \\
\hline $\mathrm{g}_{\mathrm{i}}$ & $\mid \begin{array}{l}\text { Food } \\
\text { Temperature } \\
\text { Clone } \\
\text { Food } \times \text { Temperature } \\
\text { Food } \times \text { Clone } \\
\text { Temperature } \times \text { Clone } \\
\text { Food } \times \text { Temperature } \times \text { Clone } \\
\text { Error }\end{array}$ & $\begin{array}{c}1 \\
1 \\
3 \\
1 \\
3 \\
3 \\
3 \\
142\end{array}$ & $\begin{array}{c}1995.49 \\
175.65 \\
56.43 \\
0.54 \\
14.84 \\
4.22 \\
8.32\end{array}$ & $\begin{array}{c}<0.0001 \\
<0.0001 \\
<0.0001 \\
0.4627 \\
<0.0001 \\
0.0068 \\
<0.0001\end{array}$ \\
\hline
\end{tabular}
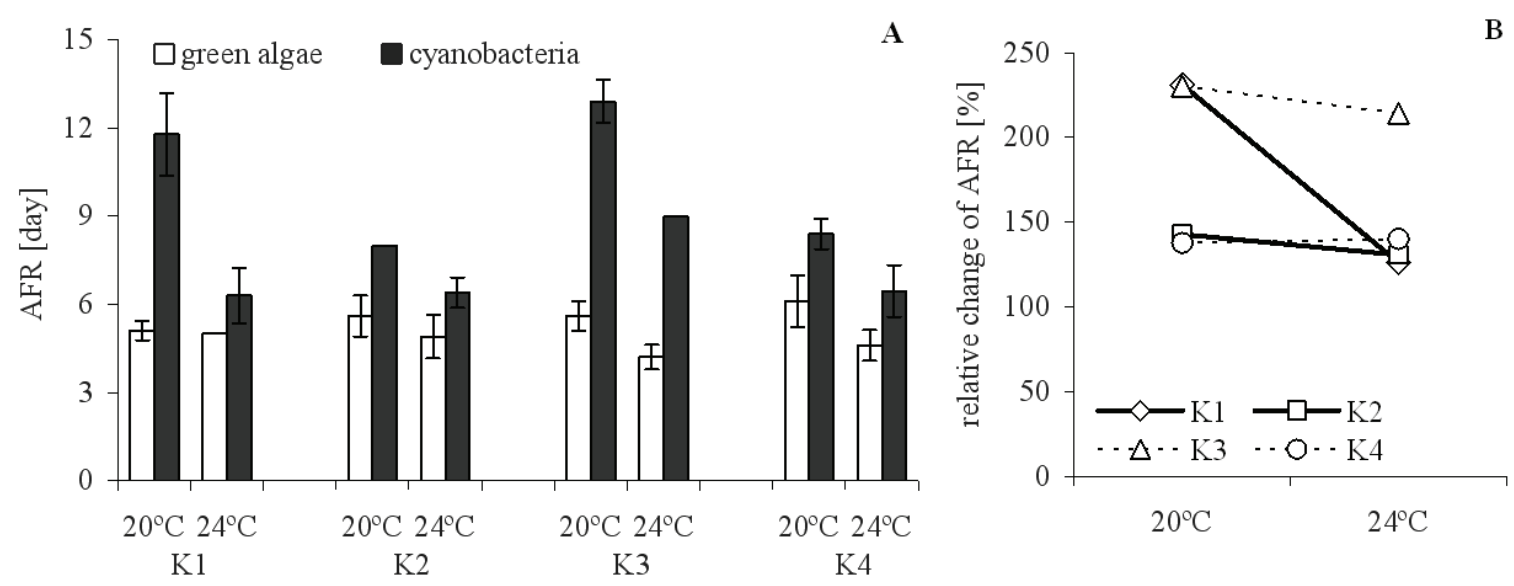

Fig. 1. Age at first reproduction (AFR) of four clones of D. magna (K1, K2, K3, K4) fed with green algae or with cyanobacteria, at two temperatures $\left(20^{\circ} \mathrm{C}\right.$ or $24^{\circ} \mathrm{C}$, left panel), and relative change of AFR (the value of the parameter in cyanobacteria treatment is expressed as a fraction of the value in green alga treatment at given temperature, right panel. Solid lines indicate a significant change; $p \leq 0.05$, Tukey).

nificantly earlier in higher temperature. Presence of cyanobacteria also resulted in a decrease of SFR of Daphnia, but the effect of cyanobacteria was more pronounced in elevated temperature only in one clone, K1. Significant differences in the number of eggs between temperature treatments were found in animals from clones $\mathrm{K} 1$ and $\mathrm{K} 3$ but only when fed with cyanobacteria. The presence of cyanobacteria slowed down the growth rate of Daphnia but only in clones K1 and K4 this effect was significantly stronger under high temperature regime (Tukey HSD post hoc analysis, $\alpha$ threshold set at 0.05 ). 


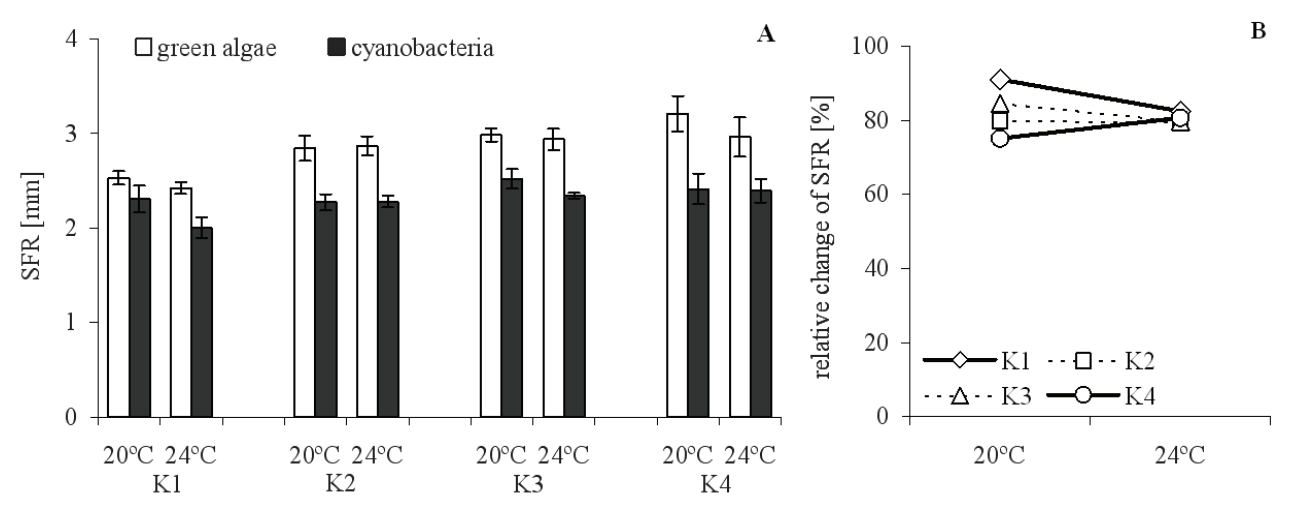

Fig. 2. Size at first reproduction (SFR) of four clones of D. magna (K1, K2, K3, K4) fed with green algae or cyanobacteria under two temperatures $\left(20^{\circ} \mathrm{C}\right.$ or $24^{\circ} \mathrm{C}$, left panel) and relative change of SFR (right panel, see caption of Fig. 1 for description).
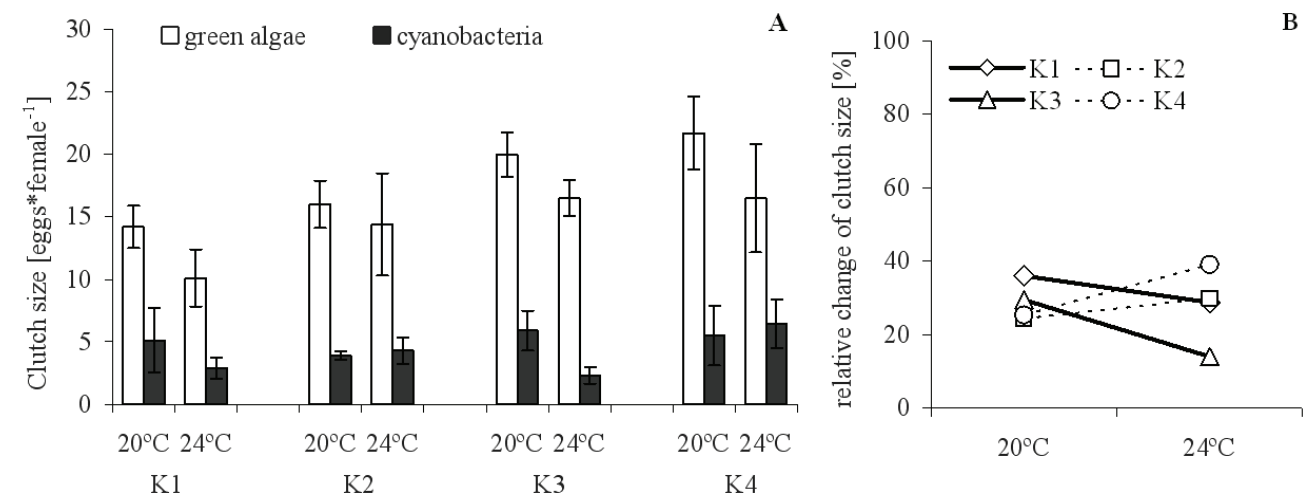

Fig. 3. Clutch size of four clones of $D$. magna $(\mathrm{K} 1, \mathrm{~K} 2, \mathrm{~K} 3, \mathrm{~K} 4)$ fed with green algae or cyanobacteria under two temperatures $\left(20^{\circ} \mathrm{C}\right.$ or $24^{\circ} \mathrm{C}$, left panel) and relative change of numbers of eggs (right panel, see caption of Fig. 1 for description).

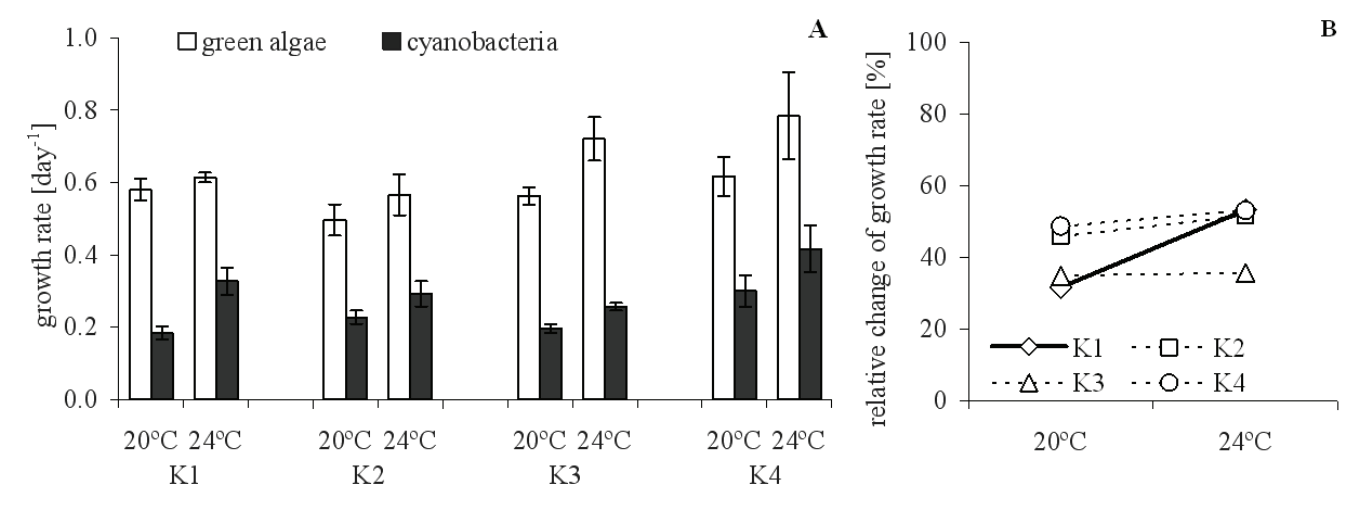

Fig. 4. Growth rate of four clones of D. magna (K1, K2, K3, K4) fed with green algae or cyanobacteria under two temperatures $\left(20^{\circ} \mathrm{C}\right.$ or $24^{\circ} \mathrm{C}$, left panel) and relative change of growth rate (right panel, see caption of Fig. 1 for description).

\section{DISCUSSION}

In accordance with previous works (Porter \& Orcutt 1980; Haney 1987; Lampert 1987a; deBernardi \& Giussani 1990; Wilson et al. 2006), this study supports the view that filamentous cyanobacteria have a negative effect on Daphnia fitness. In the presence of Cylindrospermopsis raciborskii filaments individuals from all studied clones grew slower, matured later and produced fewer eggs than in the absence of these filaments. However, unlike in few other studies (e.g., Von Elert \& Wolffrom 2001; Martin-Creuzburg et al. 2008), our results show that cyanobacteria, at least in non-axenic conditions, can sustain growth and reproduction of Daphnia, although the decrease in key life history parameters was considerably high. One potential expla- 
nation for the observed positive growth up to the reproductive age and ability to produce offspring by studied Daphnia is that the essential compounds absent in cyanobacterial food were transferred to animals by their well-fed mothers; similar maternal effects were described by Martin-Creuzburg et al. (2005). The maternal investment supplies the eggs with essential compounds, thus the suppressing effects of cyanobacterial food might be much stronger in later stages of life and later reproduction events, and particularly in subsequent generation(s). Secondly, Von Elert et al. (2003) found that the effect of feeding on low quality cyanobacterial food can be partly diminished when Daphnia can first feed on high-quality green algae at early life stage. The experimental animals in this study were born within 20 hours and stayed with their mothers in vessels containing green algae until the start of the experiments, therefore they had suitable feeding conditions in the first hours of life. Finally, our cultures were not axenic, and although the water was filtered through $0.2-\mu \mathrm{m}$ filter before the medium was prepared to reduce the number of bacteria, we cannot exclude that their growth in the media provided additional food. Nevertheless, bacteria are considered poor-quality food source for Daphnia (see Lampert 1987b for review) and lack the same essential compounds (fatty acids and sterols) as cyanobacteria; it is therefore unlikely that they supplemented the cyanobacterial diet enough to allow positive growth rate of animals that would not be possible otherwise.

Some published data suggest that the strength of the negative effect of cyanobacteria on herbivorous zooplankton, particularly large-bodied Daphnia, is positively temperature-dependent. This is so because elevated temperature (1) increases sensitivity of Daphnia to cyanotoxins (Claska \& Gilbert 1998), (2) decreases water viscosity and changes the hydrodynamics of filtering process towards strengthening the interference of cyanobacterial filaments with food collection mechanisms in Daphnia (Abrusán 2004), (3) increases sterol requirements in Daphnia (Sperfeld \& Wacker 2009) and (4) increases metabolic rate and energetic demands of Daphnia (MacArthur \& Baillie 1929) that can hardly be satisfied by cyanobacterial food of poor nutritional value. Indeed, it was suggested that observed epilimnion avoidance in Daphnia exposed to the presence of filamentous cyanobacteria (Forsyth et al. 1990; Berthon \& Brousse 1995) is an adaptive behaviour that reduces the harmful effects of cyanobacteria due to low temperature in deepwater habitats (Bednarska \& Dawidowicz 2007). One can further hypothesize that an increase in surface water temperature resulting from the global climatic trends can strengthen the inhibition of large-sized Daphnia population in temperate eutrophic lakes. Yet, this was not unambiguously supported by our results. Contrary to our expectations, the relative effect of cyanobacteria on the studied life-history parameters in our D. magna clones was in general not apparently stronger in $24{ }^{\circ} \mathrm{C}$ than in $20^{\circ} \mathrm{C}$. Under higher temperature animals maturated earlier and achieved higher growth rate. However, the relative decrease in growth rate caused by cyanobacteria was similar in the two studied temperatures and reached about half of the growth rate of animals fed with green algae. The relative delay of age at maturity due to feeding on cyanobacteria at $24{ }^{\circ} \mathrm{C}$ was similar or even smaller than at 20 ${ }^{\circ} \mathrm{C}$. Panosso \& Lürling (2010) studied the effect of $C$. raciborskii filaments on clearance rate of $D$. magna under two temperatures $\left(20^{\circ} \mathrm{C}\right.$ and $\left.27^{\circ} \mathrm{C}\right)$ and did not find a significant effect of temperature. The difference in temperatures in our study was even smaller, so we can assume that the clearance rate of animals was also similar. Thus, the feeding inhibition in animals fed with cyanobacteria within given temperature range was not likely to produce differences in life history between the temperatures.

In two of the studied clones (K1 and K3), however, we found significant relative decrease of fecundity - the key parameter for fitness - in animals fed with cyanobacteria under higher temperature. In Daphnia, a significant inter-clonal variation was found in responses to factors such as temperature (Korpelainen 1986), food concentration (Pietrzak et al. 2010), food quality (Müller-Navarra \& Lampert 1996; Weider et al. 2005), or food type (cyanobacteria vs green algae; Repka 1996). Similarly, we found that the pattern of responses to food type and/or cyanobacteria was genotype-dependent. Clone $\mathrm{K} 3$ was the most affected by the presence of cyanobacteria and performed poorly under higher temperature, whereas the effect of cyanobacteria and elevated temperature on clone $\mathrm{K} 2$ was negligible. The clones used in the studies originated from a shallow pond located near the center of Warsaw. During the growing season, the pond Daphnia population is exposed to varying - sometimes extremely high - temperatures. It is therefore not surprising that warm wateradapted clones, such as our clone $\mathrm{K} 2$, are present among the lineages raised from resting eggs collected in this pond. Although we have not performed any artificial selection experiments, we presume that continuous exposure of Daphnia populations to elevated temperature can result in clonal selection, similar to the enhanced microevolution driven by temperature rise alone reported by Van Doorslaer et al. (2009). Varying sensitivity to temperature may strongly interact with the differences in vulnerability to presence of cyanobacteria, and, consequently, may lead to rapid microevolutionary shifts in such populations.

\section{CONCLUSION}

We conclude that elevated temperature can strengthen the negative effect of cyanobacteria on largesized cladoceran, Daphnia magna, but this result is not general for all studied clones and for all measured life history parameters. It is unlikely that increase of water 
temperature and development of warm-water cyanobacteria will lead to elimination of Daphnia magna from surface waters, however, it will certainly lead to selection of better adapted clones and thus lead to microevolutionary changes in populations of this species.

\section{ACKNOWLEDGMENTS}

We would like to thank Jaromír Sed'a, Adam Petrusek and two anonymous reviewers for critical comments which helped to improve the manuscript. Funding was provided by the research grant from the Polish Committee for Scientific Research "Cyanobacteria - planktonic cladocerans interaction under forecasted global warming conditions" (No: N N304 067236 )

\section{REFERENCES}

Abrusán, G. 2004. Filamentous cyanobacteria, temperature and Daphnia growth: The role of fluid mechanics. Oecologia, 141: 395-401.

Bednarska, A. \& P. Dawidowicz. 2007. Change in filterscreen morphology and depth selection: uncoupled responses of Daphnia to the presence of filamentous cyanobacteria. Limnol. Oceanogr., 52: 2358-2363.

Berthon, J.L., \& S. Brousse. 1995. Modification of migratory behavior of planktonic Crustacea in the presence of a bloom of Microcystis aeruginosa (Cyanobacteria). Hydrobiologia, 300/301: 185-193.

Briand, J.-F., C. Leboulanger, J.-F. Humbert, C. Bernard \& P. Dufour. 2004. Cylindrospermopsis raciborskii (Cyanobacteria) invasion at mid-latitudes: Selection, wide physiological tolerance, or global warming? J. Phycol., 40: 231-238.

Claska, M.E. \& J.J.Gilbert. 1998. The effect of temperature on the response of Daphnia to toxic cyanobacterium. Freshwat. Biol., 39: 221-232.

deBernardi, R. \& G. Giussani. 1990. Are blue-green algae a suitable food for zooplankton? An Overview. Hydrobiologia, 200/201: 29-41.

DeMott, W.R. 1999. Foraging strategies and growth inhibition in five daphnids feeding on mixtures of a toxic cyanobacterium and a green alga. Freshwat. Biol., 42: 263-274.

Forsyth, D.J., M.R., James \& M. Cryer. 1990. Alteration of seasonal and diel patterns in vertical migration of zooplankton by Anabaena and planktivorous fish. Arch. Hydrobiol., 117: 385-404.

Gliwicz, Z.M. \& E. Siedlar. 1980. Food size limitation and algae interfering with food collection in Daphnia. Arch. Hydrobiol., 88: 155-177.

Haney, J.F. 1987. Field studies on zooplankton-cyanobacteria interactions. N.Z.J. Mar. Freshw. Res., 21: 467-475.

IPCC 2007: Summary for Policymakers. In: Solomon S., Qin D., Manning M., Chen Z., Marquis M., Averyt K.B., Tignor M., \& Miller H.L. (Eds), Climate Change 2007: The Physical Science Basis. Contribution of Working Group I to the Fourth Assessment Report of the Intergovernmental Panel on Climate Change. Cambridge University Press, Cambridge, United Kingdom and New York, USA.

Korpelainen, H. 1986. The effects of temperature and photoperiod on life-history parameters of Daphnia magna (Crustacea: Cladocera). Freshwat. Biol., 16: 615-620.

Lampert, W. 1987a. Laboratory studies on zooplankton-cyanobacteria interactions. N.Z.J. Mar. Freshw. Res., 21: 483-490.

Lampert, W. 1987b. Feeding and nutrition in Daphnia. In: R.H. Peters \&, R. de Bernardi. (Eds), Daphnia. Mem. Ist. ital Idrobiol., 45: 143-192.

Lampert, W. \& U. Sommer. 1993. Limnoökologie. Georg. Thieme Verlag Stuttgart, New York.
MacArthur, J.W. \& W.H.T. Baillie. 1929. Metabolic activity and duration of life. II. Metabolic rates and their relation to longevity in Daphnia magna. J. Exp. Zool., 53: 243-268.

Martin-Creuzburg, D., A. Wacker \& E. Von Elert. 2005. Life history consequences of sterol availability in the aquatic keystone species Daphnia. Oecologia, 144: 362-372.

Martin-Creuzburg, D., E. Von Elert \& K.H. Hoffmann. 2008. Nutritional constraints at the cyanobacteria-Daphnia magna interface: The role of sterols. Limnol. Oceanogr., 53: 456-468.

Müller-Navarra, D. \& W. Lampert. 1996. Seasonal patterns of food limitation in Daphnia galeata: Separating food quantity and food quality effects. J. Plankton Res., 18: 1137-1157.

Padisák, J. 1997. Cylindrospermopsis raciborskii (Woloszynska) Seenayya et Subba Raju, an expanding, highly adaptative cyanobacterium: worldwide distribution and review of its ecology. Arch. Hydrobiolol., 107(Suppl.): 563-593.

Paerl, H.W. \& J. Huisman. 2008. Climate: Blooms like it hot. Science, 320: 57-58.

Panosso, R. \& M. Lürling. 2010. Daphnia magna feeding on Cylindrospermopsis raciborskii: The role of food composition, filament length and body size. J. Plankton Res., 32: 1393-1404.

Porter, K.G., \& J.D. Orcutt. 1980. Nutritional adequacy, manageability, and toxicity as factors that determine the food quality of green and blue-green algae for Daphnia. In: W.C. Kerfoot (Ed.), Evolution and ecology of zooplankton communities. University Press, Hanover, London: 282-291.

Pietrzak, B., M. Grzesiuk \& A. Bednarska. 2010. Food quantity shapes life history and survival strategies in Daphnia magna (Cladocera). Hydrobiologia, 364: 51-54.

Rapala, J. \& K. Sivonen. 1998. Assessment of environmental conditions that favor hepatotoxic and neurotoxic Anabaena spp. strains cultured under light limitation at different temperatures. Microbial Ecol., 36: 181-192.

Repka, S. 1996. Inter- and intraspecific differences in Daphnia life history in response to two food sources: the green algae Scenedesmus and the filamentous cyanobacteria Oscillatoria. J. Plankton Res., 18: 1213-1223.

Sperfeld, E \& A. Wacker 2009. Effects of temperature and dietary sterol availability on growth and cholesterol allocation of the aquatic keystone species Daphnia. J. Exp. Biol., 212: 3051-3059.

Threlkeld, S.T. 1979. The midsummer dynamics of two Daphnia species in wintergreen lake, Michigan. Ecology, 60: 165-179.

Wiedner, C., J. Rücker, R. Brüggeman \& B. Nixdorf. 2007. Climate change affects timing and size of populations of an invasive cyanobacterium in temperate regions. Oecologia, 152: 473-484.

Weider, L.J., W., Makino, K., Acharya, K.L., Glenn, M., Kyle, J., Urabe, \& J.J. Elser. 2005. Genotype $\times$ environment interactions, stoichiometric food quality effects, and clonal coexistence in Daphnia pulex. Oecologia, 143: 537-547.

Wilson, A.E., O.Sarnelle \& A.R. Tillmanns. 2006. Effects of cyanobacterial toxicity and morphology on the population growth of freshwater zooplankton: Meta-analyses of laboratory experiments. Limnol. Oceanogr., 51: 1915-1924.

Wetzel, R.G. 2001 Limnology: Lake and River Ecosystems, $3^{\text {rd }}$ ed. Academic Press, San Diego, California, USA.

Van Doorslaer, W., R. Stoks, C. Duvivier, A. Bednarska \& L. De Meester. 2009. Population dynamics determine genetic adaptation to temperature in Daphnia. Evolution, 63: 1867-1878.

Von Elert, E., D. Martin-Creuzburg \& J.R. Le Coz. 2003. Absence of sterols constrains carbon transfer between cyanobacteria and a freshwater herbivore (D. galeata). Proc. $R$. Soc. Lond. B, 207: 1209-1214.

Von Elert, E., \& T. Wolffrom. 2001. Supplementation of cyanobacteria food with polyunsaturated fatty acids does not improve growth of Daphnia. Limnol. Oceanogr., 46: 1552-1558. 